\title{
Effects of Polyaniline Additive in Solvent-Free Ionic Liquid Electrolyte for Dye-Sensitized Solar Cell ${ }^{\dagger}$
}

\author{
Jae Kwan Lee, ${ }^{*}$ Narayan Chandra Deb Nath, ${ }^{\ddagger}$ Eun Hee Cha, Subrata Sarker, ${ }^{\ddagger}$ Hyung Soon Park, ${ }^{\S}$ Woo-Sung Jeong, ${ }^{\S}$ \\ Seok-Ho Hong, ${ }^{\S}$ and Jae-Joon Lee ${ }^{\ddagger, \#, *}$ \\ Department of Green Energy \& Research Center for Convergence Technology, Hoseo University, \\ Chungnam 336-795, Korea. *E-mail: jklee@hoseo.edu \\ ${ }^{\ddagger}$ Department of Advanced Technology Fusion, Konkuk University, Seoul 143-701, Korea. *E-mail: jjlee@kku.ac.kr \\ ${ }^{\S}$ Probiond Co. Ltd, Konkuk University, Seoul 143-701, Korea \\ ${ }^{\#}$ Department of Applied Chemistry, Konkuk University, Chungju 380-701, Korea \\ Received September 4, 2010, Accepted October 20, 2010
}

Key Words: Polyaniline, Ionic liquid, Dye-sensitized solar cell, Quasi-solid electrolyte, Interfacial electron transfer

The success of the dye-sensitized photoelectrochemical cell developed by Grätzel and co-workers ${ }^{1}$ helped to reinvigorate the search for alternatives to traditional semiconductor photovoltaics in the early 1990s. Although the dye-sensitized solar cell achieved over $11 \%$ power conversion efficiency under AM $1.5 \mathrm{G},{ }^{2}$ however, the less operational stability of device such as the leakage of liquid electrolyte was often limited for commercialization. ${ }^{3}$ The enormous efforts for the non-volatile electrolytes such as solvent-free ionic liquids (ILs) and the quasi-solidstate electrolytes with polymer and gelators such as organic and inorganic materials have focused on improving the device performances and stabilities through developments of efficient materials to overcome this problem. ${ }^{4-6}$ Among them, solvent-free IL electrolytes has been extensively demonstrated with attractive advantages regarding thermal stability, non-flammability, and highly ionic conductivity to realizing commercial production as well as to realizing flexible device, in which molecular solvent may be strongly imposed restriction due to their permeability into plastic substrate. ${ }^{7-9}$

Recently, the respectable efficiency of over $5 \%$ was obtained from the photovoltaic cell composed with the amphiphilic ruthenium dye, cis-RuLL'(SCN) $2(L=4,4$ '-dicarboxylic acid2,2'-bipyridine, $\mathrm{L}^{\prime}=4,4^{\prime}$-dinonyl-2,2'-bypyridine) (Z907), and 1-methyl-3-propylimidazolium iodide (PMI-I). ${ }^{8}$ And an outstanding achievement has been reported by Grätzel et al. with providing a promising efficiency of over $8 \%$ by using eutectic melt-based IL electrolytes. ${ }^{9}$ And an incorporating of some additives in solvent-free IL electrolytes has exhibited the enhanced performance of device. In this perspective, we have also attempted new approaches to improve the ion transporting properties in solvent-free IL electrolytes by conjugated polymer additive. We herein, report the effects of polyaniline (PANI) additive in solvent-free IL electrolyte for dye-sensitized solar cell.

Recently, PANI doped by acid or base has been investigated as alternatives of inorganic electrodes due to its flexible, solution processible, and high conductive metallic properties. ${ }^{10} \mathrm{Al}-$ though the conducting PANI has been also employed as electrolyte in the solid-state dye-sensitized solar cell, ${ }^{11-12}$ the large

\footnotetext{
${ }^{\top}$ This paper is dedicated to Professor Hasuck Kim for his outstanding contribution to electrochemistry and analytical chemistry.
}

molecular size and poor solubility in solvent have limited the success of this approach. Moreover, high conductivity of the doped PANI can be exhibited in high molecular weight, which makes it difficult to infiltrate into the porous $\mathrm{TiO}_{2}$ film. Therefore, highly conducting PANI may not be efficiently applied as solid-state electrolyte for dye-sensitized solar cell.

In this report, we describe the unique effects of PANI additive in solvent-free IL electrolyte system in dye-sensitized solar cell. The low molecular weight $(\sim 10,000)$ of PANI was used to facilitate the infiltration into porous $\mathrm{TiO}_{2}$ film and the nonconducting undoped emeraldine base (EB) structure of PANI was also employed to induce the self-assembled nanostructure by $\pi-\pi$ interaction with imidazolium-based IL which can exhibit quasi-solid state with the enhanced structural rigidity of PANI in solvent-free IL electrolyte shown in Figure 1.

According to our recent results about the physical and electrochemical properties of PANI/IL composite, the quasi-solidification was presented in imidazolium-based IL (PMI-I) containing above $30 \mathrm{wt} \%$ of PANI EB, which exhibited around $80 \%$ decrease of conductivity compared to pristine PMI-I. ${ }^{13}$ Based on this preliminary results, we investigated the effects of polyaniline as unique additive in two binary electrolytes (Electrolyte A/Electrolyte B) without/with $N$-methylbenzimidazole (NMB) containing PMI-I and 1-ethyl-3-methylimidazolium dicyan-

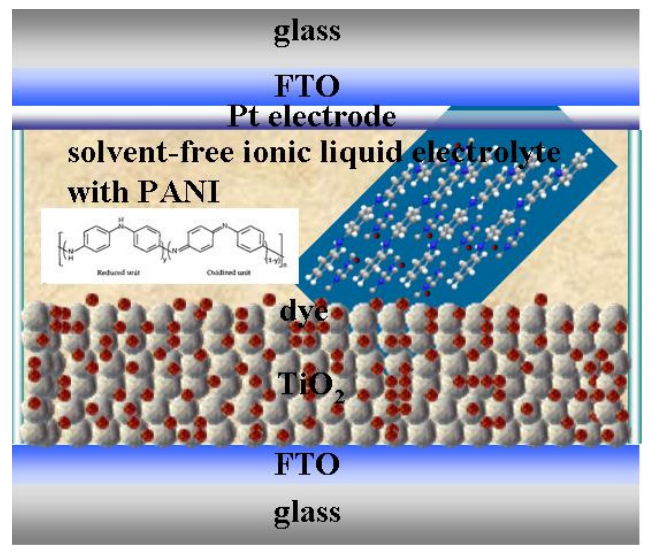

Figure 1. Schematic depiction of structural rigidity of PANI in solventfree IL electrolyte for dye-sensitized solar cell. 

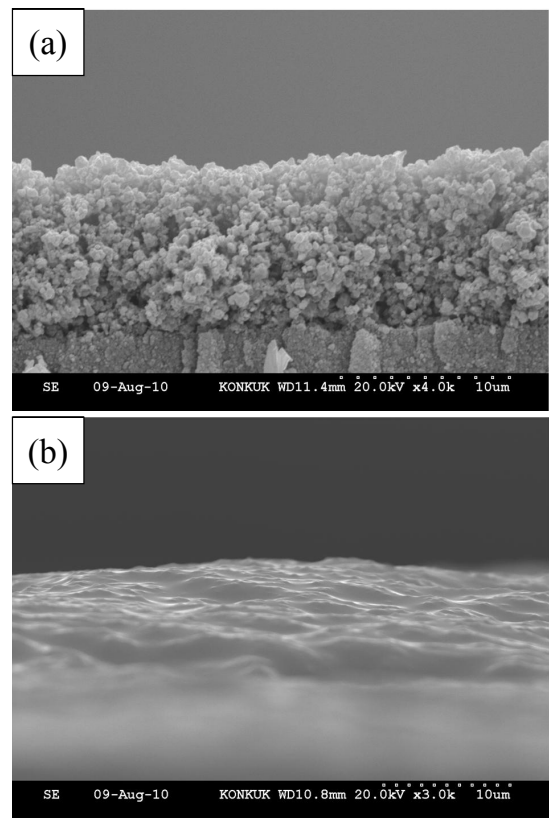

Figure 2. SEM images of cross-section of $\mathrm{TiO}_{2}$ film without (a)/with (b) solvent-free ionic liquid electrolyte containing $20 \mathrm{wt} \%$ PANI.

amide (EMI-DCA) (65/35 v/v) for Z907 dye-sensitized solar cell, which conditions exhibited the moderate photovoltaic performances in previous reports.

Figure 2 shows the scanning electron microscope (SEM) images of cross-section of $\mathrm{TiO}_{2}$ film which was used in this study. The $\mathrm{TiO}_{2}$ layer $(\sim 10 \mu \mathrm{m})$ was composed of the nanocrytalline $\mathrm{TiO}_{2}$ layer $(4 \mu \mathrm{m})$ and scattering $\mathrm{TiO}_{2}$ layer $(6 \mu \mathrm{m})$. Although the distinct features of $\mathrm{TiO}_{2}$ nanoparticle and layer were observed in Figure 2a, the film after treatment with electrolyte of $20 \mathrm{wt} \%$ PANI presents the typical cross-sectional image of $\mathrm{TiO}_{2}$ film, which can not show the feature of $\mathrm{TiO}_{2}$ nanoparticle and layer, containing electrolyte shown in Figure 2b. This indicates that the electrolyte containing PANI additive which was quasi-solidified can infiltrate into the nanoporous $\mathrm{TiO}_{2}$ film due to the rather small molecular size by low molecular weight of PANI. Therefore, we note that this PANI can be employed as additive in solvent-free IL electrolyte for dyesensitized solar cell.

Figure 3 shows the features of binary electrolyte with PANI additive. The quasi-solidification was observed in the binary electrolyte $\mathrm{A}$ and $\mathrm{B}$ with above $30 \mathrm{wt} \%$ and $20 \mathrm{wt} \%$ of PANI additive respectively. As shown in Figure $3 \mathrm{a}$, the more addition of PANI, the stickier of the solvent-free IL electrolyte. And the quasi-solid of the electrolyte with PANI additive was also shown in Figure 3b. The surface of this quasi-solid seems to be the flower-like nanosheet from SEM image of Figure $3 \mathrm{c}$. From these results, we note that PANI additive can induce the selfassembled nanostructure by $\pi-\pi$ interaction with imidazoliumbased IL which can exhibit quasi-solid state with the enhanced structural rigidity of PANI in solvent-free IL electrolyte.

We investigated the characteristics of sandwich-type dyesensitized solar cells based on $\mathrm{TiO}_{2}$ nanocrystalline and scattering layer, Z907 dye, Pt counter electrode, and solvent-free binary IL electrolyte with/without PANI additive. And the current-
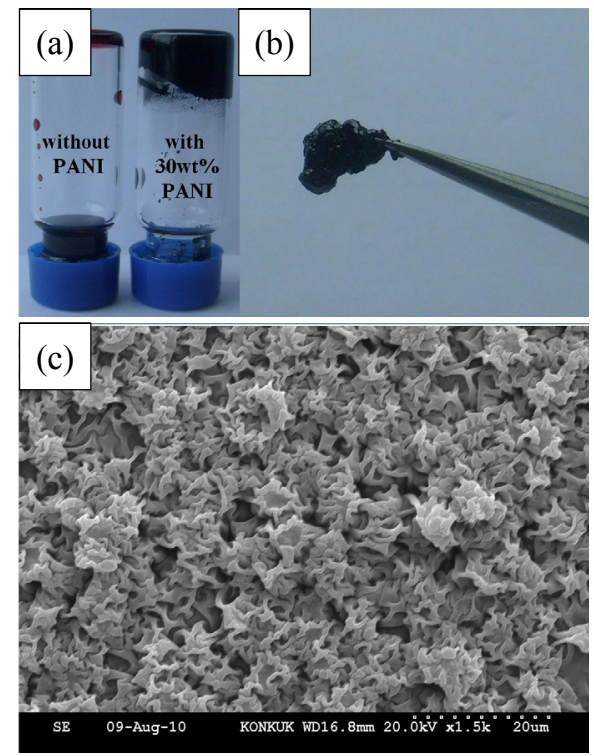

Figure 3. Photograph of binary electrolyte without/with PANI additive (a) and photograph (b) and SEM image (c) of quasi-solidified electrolyte with $20 \mathrm{wt} \%$ PANI.

(a)

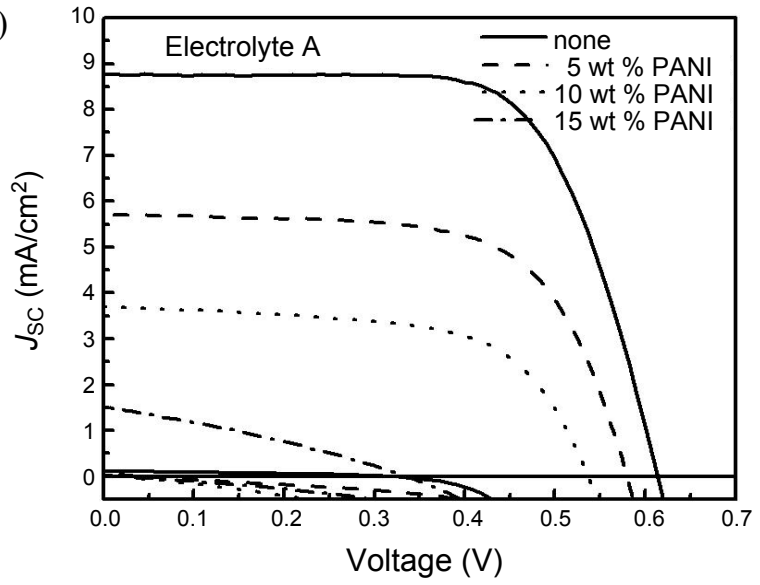

(b)

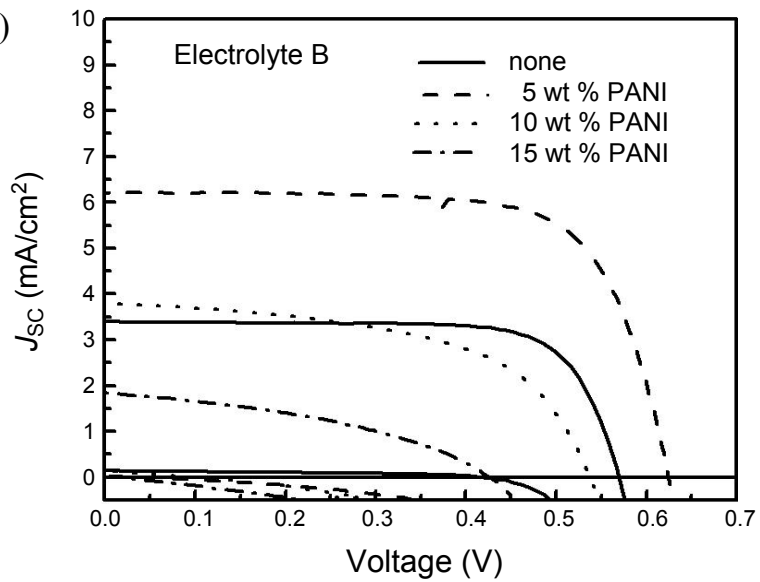

Figure 4. Current-voltage curves of sandwich-type dye-sensitized solar cells fabricated by solvent-free ionic liquid electrolyte A (a) and electrolyte B (b) with/without PANI additive. 
voltage curves of these devices are showed in Figure 4. Also, the output characteristics of devices are summarized in Table 1. As shown in Figure 4 and Table 1, the reference device with electrolyte A without PANI additive exhibited the moderate performance; $8.78 \mathrm{~mA} / \mathrm{cm}^{2}$ of short circuit current $(J \mathrm{sc}), 0.61 \mathrm{~V}$ of open circuit voltage $(V \mathrm{oc}), 68.3 \%$ of the fill factor $(F F)$ and $3.68 \%$ of an efficiency, but electrolyte B in which the NMB was added reduce the $J_{\mathrm{sc}}$ and $V \mathrm{oc}$ and increase a little of $F F$. In many cases, it has been reported that the small molecule additives such as NMB and $t$-butylpyridine (TBP) can play a role of improving the Voc by inducement of the conduction band of the $\mathrm{TiO}_{2}$ electrode more negatively. But we observed that the NMB in this solvent-free binary IL electrolyte system affected adversely the photovoltaic performances. The photovoltaic performance of device fabricated by electrolyte A with $5 \mathrm{wt} \%$ PANI was reduced around $24 \%$ compared to that without PANI; 5.71 $\mathrm{mA} / \mathrm{cm}^{2}$ of $J_{\mathrm{sc}}, 0.58 \mathrm{~V}$ of $V \mathrm{oc}, 65.7 \%$ of $F F$ and $2.81 \%$ of efficiency. On the contrary, the photovoltaic performance of device fabricated by electrolyte B with 5 wt \% PANI was increased around $90 \%$ compared to that without PANI; $6.20 \mathrm{~mA} / \mathrm{cm}^{2}$ of $J_{\mathrm{sc}}, 0.63 \mathrm{~V}$ of $V \mathrm{oc}, 71.6 \%$ of $F F$ and $2.77 \%$ of efficiency. From these results, we guess that the PANI additive may interrupt the adsorption of NMB on $\mathrm{TiO}_{2}$ surface by $\pi-\pi$ interaction of the NMB and PANI in electrolyte B. It can be understood by that the quasi-solidification of electrolyte $\mathrm{B}$ was observed in lower concentration of PANI than that of electrolyte A. This notes that the addition of PANI can remove the negative influence of solvent-free binary electrolyte by NMB. In addition of above $10 \mathrm{wt} \%$ PANI, all devices fabricated by electrolyte A or electrolyte B exhibited the remarkably reduced performances. These can be caused by low ion-transport in solvent-free IL electrolyte since the viscosity of electrolyte is rapidly increased with quasi-solidifying in higher concentration of PANI.

Table 1. Photovoltaic performances of sandwich-type dye-sensitized solar cells fabricated by solvent-free ionic liquid electrolytes with/ without PANI additive ${ }^{a}$

\begin{tabular}{ccccc}
\hline Additive & $\begin{array}{c}J_{\mathrm{sc}} \\
\left(\mathrm{mA} / \mathrm{cm}^{2}\right)\end{array}$ & $\begin{array}{c}\text { Voc } \\
(\mathrm{V})\end{array}$ & $\begin{array}{c}F F \\
(\%)\end{array}$ & $\begin{array}{c}\text { Efficiency } \\
(\%)\end{array}$ \\
\hline Electrolyte A & 8.78 & 0.61 & 68.3 & 3.68 \\
\hline $\begin{array}{c}\text { Electrolyte B } \\
\text { Electrolyte A, } \\
5 \text { wt \% PANI }\end{array}$ & 3.39 & 0.57 & 74.7 & 1.44 \\
\hline $\begin{array}{l}\text { Electrolyte B, } \\
5 \text { wt \% PANI }\end{array}$ & 6.71 & 0.58 & 65.7 & 2.81 \\
$\begin{array}{l}\text { Electrolyte A, } \\
10 \text { wt \% PANI }\end{array}$ & 3.71 & 0.54 & 61.6 & 1.23 \\
\hline $\begin{array}{l}\text { Electrolyte B, } \\
10 \text { wt \% PANI }\end{array}$ & 3.74 & 0.54 & 54.6 & 1.09 \\
\hline $\begin{array}{l}\text { Electrolyte A, } \\
15 \text { wt \% PANI }\end{array}$ & 1.52 & 0.34 & 30.0 & 0.15 \\
\hline $\begin{array}{l}\text { Electrolyte B, } \\
15 \text { wt \% PANI }\end{array}$ & 1.84 & 0.40 & 39.5 & 0.31 \\
\hline
\end{tabular}

${ }^{a}$ Electrolyte A was composed of of $0.2 \mathrm{M}$ iodine in PMI-I:EMD-DCA (65/35), and electrolyte B was composed of $0.2 \mathrm{M}$ iodine, $0.5 \mathrm{M} \mathrm{NMB}$ in PMI-I:EMD-DCA (65/35). The performances are determined under simulated $100 \mathrm{~mW} / \mathrm{cm}^{2} \mathrm{AM} 1.5 \mathrm{G}$ illumination. The light intensity using calibrated standard silicon solar cells with a proactive window made from KG5 filter glass traced to the National Renewable Energy Laboratory (NREL). The active area of device is $0.185 \mathrm{~cm}^{2}$.
Electrochemical impedance spectroscopy (EIS) is an important tool to elucidate the kinetics of interfacial electron transfer processes in DSSCs. In the Nyquist plot, the first semicircle can be attributed to the electrochemical reaction resistance at the Pt counter electrode in the high-frequency region. The middle arc indicate the charge transfer resistance at the $\mathrm{TiO}_{2} /$ electrolyte interface in the mid-frequency region while the third one related to the diffusion of ions in electrolyte. ${ }^{14,15}$ The diameter of the middle semicircle defines the charge transfer resistance related with the back reaction transfer of electron to the oxidized form $\left(\mathrm{I}_{3}{ }^{-}\right)$of redox messenger in the electrolyte. ${ }^{16}$ A higher back reaction rate, correspond to the decrease of open circuit voltage, could be expected when the charge transfer resistance is smaller. ${ }^{17}$ Figure 5 shows the impedance spectra of devices fabricated by electrolyte A and electrolyte B without/with $5 \mathrm{wt} \%$ PANI under light illumination. In the Nyquist plot, the resistances at $\mathrm{TiO}_{2}$ /electrolyte interface for the electrolytes without PANI is quite low. They also show higher diffusion of ions. But the devices fabricated by electrolyte B exhibited larger middle circle of impedance spectrum than that by electrolyte $A$. The dark current of devices fabricated by electrolyte B is lower than by electrolyte A as shown Figure 4. But, the lower values of photocurrent and voltage were observed in the devices fabricated by electrolyte $\mathrm{B}$ under light illumination compared to that by electrolyte A. From these results, the NMB additive in solvent-free IL electrolyte can makes the interfacial resistance of $\mathrm{TiO}_{2} /$ electrolyte, but influence the Fermi level of $\mathrm{TiO}_{2}$ by adsorbing of $\mathrm{NMB}$ on $\mathrm{TiO}_{2}$ surface, resulting in exhibition of lower photovoltaic performances. The lower performance of device fabricated by electrolyte A with PANI additive could be caused by the similar effects with NMB additive through impedance spectra and I-V curves of Figure 5 and 4 respectively. On the other hands, the PANI additive in electrolyte B can be competitive with the NMB additive by interrupting the adsorption of $\mathrm{NMB}$ on $\mathrm{TiO}_{2}$ surface by $\pi-\pi$ interaction of the NMB and PANI, resulting in recovery of photovoltaic performance lowered by NMB. Besides, the interfacial resistances become larger after adding PANI into the electrolytes. It can be attributed to the significant decrease of ion diffusion rate and the formation of blocking layers at $\mathrm{TiO}_{2} /$ electrolyte interface due to $\pi-\pi$ interaction with imidazolium-based IL. It is consistent

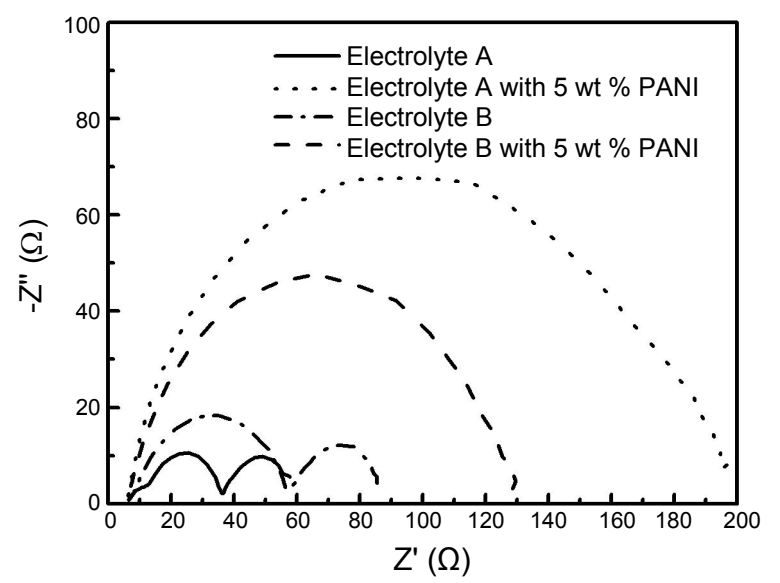

Figure 5. Impedance spectra of sandwich-type dye-sensitized solar cells fabricated by electrolyte A and electrolyte B without/with 5 wt \% PANI under 1 sun illumination. 
with the impedance spectra of the electrolytes with PANI showing higher diameter for middle-semicircle with the third semicircle almost disappeared. In higher concentration of above $10 \mathrm{wt} \%$ PANI additive showed the similar performances in both electrolyte A and B. These may caused by that the markedly enhanced viscosity of electrolytes with PANI, which can affect the ion diffusion rate and dye regeneration negatively.

In summary, we have demonstrated the unique effects of PANI additive in solvent-free IL electrolyte system in dye-sensitized solar cell, which was investigated in two binary electrolytes (Electrolyte A/Electrolyte B) without/with $N$-methylbenzimidazole (NMB) containing PMI-I and 1-ethyl-3-methylimidazolium dicyanamide (EMI-DCA) (65/35 v/v) for Z907 dye-sensitized solar cell. The quasi-solidification was observed in the binary electrolyte A and B with above $30 \mathrm{wt} \%$ and 20 wt $\%$ of PANI additive respectively, resulting in the selfassembled nanostructure by $\pi-\pi$ interaction with imidazoliumbased IL. Although these results were obtained under not optimized device condition, the results note that the PANI has affected the feature of electrolyte in photovoltaic performance competitively with NMB additive. The further study using PANI additive in solvent-free ionic liquid electrolyte for dye-sensitized solar cell is in progress.

\section{Experimental Section}

Ionic liquids (PMI-I and EMI-DCA) used in this study are commercially available. And PANI was obtained from Elpani Co., Ltd.; Mn (7,448), Mw (12,426), PDI (1.67), I.V. (0.22), and conductivity $(12 \mathrm{~S} / \mathrm{cm})$. It shows the good solubility in 1- $N$-methyl-2-pyrrolidinone (NMP) or tetrahydrofuran (THF). FTO glass plates (Pilkington TEC Glass-TEC 8, Solar $2.3 \mathrm{~mm}$ thickness) were cleaned in a detergent solution using an ultrasonic bath for $30 \mathrm{~min}$, rinsed with water and ethanol. The FTO glass plates were immersed in $40 \mathrm{mM} \mathrm{TiCl}_{4}$ (aqueous) at $70{ }^{\circ} \mathrm{C}$ for $30 \mathrm{~min}$ and washed with water and ethanol. A transparent nanocrystalline layer on the FTO glass plate was prepared by doctor blade printing $\mathrm{TiO}_{2}$ paste (Solaronix, Ti-Nanoxide T/SP) and then dried for $2 \mathrm{~h}$ at $25^{\circ} \mathrm{C}$. The $\mathrm{TiO}_{2}$ electrodes were gradually heated under an air flow at $325^{\circ} \mathrm{C}$ for $5 \mathrm{~min}$, at $375^{\circ} \mathrm{C}$ for $5 \mathrm{~min}$, at $450{ }^{\circ} \mathrm{C}$ for $15 \mathrm{~min}$, and at $500{ }^{\circ} \mathrm{C}$ for $15 \mathrm{~min}$. The thickness of the transparent layer was measured by using an Alpha-step 250 surface profilometer (Tencor Instruments, San Jose, CA), a paste for the scattering layer containing $400 \mathrm{~nm}$ sized anatase particles (CCIC, PST-400C) was deposited by doctor blade printing and then dried for $2 \mathrm{~h}$ at $25^{\circ} \mathrm{C}$. The $\mathrm{TiO}_{2}$ electrodes were gradually heated under an air flow at $325^{\circ} \mathrm{C}$ for $5 \mathrm{~min}$, at $375^{\circ} \mathrm{C}$ for $5 \mathrm{~min}$, at $450{ }^{\circ} \mathrm{C}$ for $15 \mathrm{~min}$, and at $500^{\circ} \mathrm{C}$ for $15 \mathrm{~min}$. The resulting layer was composed of $6 \mu \mathrm{m}$ thickness of transparent layer and $4 \mu \mathrm{m}$ thickness of scattering layer. The $\mathrm{TiO}_{2}$ electrodes were treated again by $\mathrm{TiCl}_{4}$ at $70{ }^{\circ} \mathrm{C}$ for $30 \mathrm{~min}$ and sintered at $500{ }^{\circ} \mathrm{C}$ for $30 \mathrm{~min}$. The $\mathrm{TiO}_{2}$ electrodes were immersed into the $\mathrm{Z} 907$ (0.3 $\mathrm{mM}$ in ethanol) and kept at room temperature for $12 \mathrm{~h}$. The FTO plate (Pilkington TEC Glass-TEC 8, Solar $2.3 \mathrm{~mm}$ thickness) for counter electrodes cleaned with ultrasonic bath in $\mathrm{H}_{2} \mathrm{O}$, acetone and $0.1 \mathrm{M} \mathrm{HCl}$ $a q$., subsequently. Counter electrodes were prepared by coating with a drop of $\mathrm{H}_{2} \mathrm{PtCl}_{6}$ solution ( $2 \mathrm{mg}$ of Pt in $1 \mathrm{~mL}$ of ethanol) on a FTO plate and heating at $400{ }^{\circ} \mathrm{C}$ for $15 \mathrm{~min}$. The dye adsorbed
$\mathrm{TiO}_{2}$ electrode and Pt-counter electrode were assembled into a clipped sandwich-type cell with an ionomer film (Surlyn SX 1170-25, Solaronix) as a spacer between the electrodes. A drop of electrolyte solutions (electrolyte A of $0.2 \mathrm{M}$ iodine in PMI-I: EMD-DCA (65/35), electrolyte B of $0.2 \mathrm{M}$ iodine, $0.5 \mathrm{M} \mathrm{NMB}$ in PMI-I:EMD-DCA (65/35)) with/without PANI additive was placed between the electrodes of the assembled cell. The performance of the cells was examined. Their current densityvoltage $(J-V)$ curves were measured at 1 sun $\left(100 \mathrm{~mW}\right.$ per $\mathrm{cm}^{2}$, AM 1.5) using a Keithley Model 2400 and a 1000 W Xenon lamp (91193, Oriel). Then we calibrated the light intensity using calibrated standard silicon solar cells with a proactive window made from KG5 filter glass traced to the National Renewable Energy Laboratory (NREL). The active area of the cells was about $0.185 \mathrm{~cm}^{2}$.

Acknowledgments. This work was supported by the Small \& Medium Business Administration (SMBA) of Korea (S1054 490), the National Research Foundation of Korea (NRF) grant funded by the Korea government (MEST) (No. 2008-0062166), and by Seoul R\&BD Program (WR090671). It was supported partly by the New \& Renewable Energy program of the Korea Institute of Energy Technology Evaluation and Planning (KETEP) grant funded by the Korea government Ministry of Knowledge Economy and by the New IT Project (NO. 2010-C-1-BY0-A-18) for growth foothold of green-semiconductor industry based on IT of the Chungcheong Leading Industry Office of the Korean Ministry of Knowledge Economy.

\section{References}

1. O’Regan, B.; Grätzel, M. Nature 1991, 353, 737.

2. Nazeeruddin, M. K.; De Angelis, F; Fantacci, S.; Selloni, A.; Viscardi, G.; Liska, P.; Ito, S.; Takeru, B.; Grätzel, M. J. Am. Chem. Soc. 2005, 127, 16835.

3. Noda, S.; Nagano, K.; Inoue, E.; Egi, T.; Nakashima, T.; Imawaka, N.; Kanayama, M.; Iwata, S.; Toshima, K.; Nakada, K.; Yoshino, K. Syn. Metals 2009, 159, 2355.

4. Wang, P.; Zakeeruddin, S. M.; Comte, P.; Exnar, I.; Grätzel, M. J. Am. Chem. Soc. 2003, 125, 1166.

5. Stathatosa, E.; Lianos, P.; Jovanovski, V.; Orel, B. J. Photochem. Photobio. A: Chem. 2005, 169, 57.

6. Huo, Z.; Dai, S.; Wang, K.; Kong, F.; Zhang, C.; Pan, X.; Fang, X. Solar Energy Mater. Solar Cells 2007, 91, 1959.

7. Wang, P.; Zakeeruddin, S. M.; Exnar, I.; Grätzel, M. Chem. Commun. 2002, 2972.

8. Gorlov, M.; Kloo, L. Dalton Trans. 2008, 2655.

9. Bai, Y.; Cao, Y.; Zhang, J.; Wang, M.; Li, R.; Wnag, P.; Zakeeruddin, S. M.; Grätzel, M. Nat. Mater. 2008, 7, 626.

10. Lee, K.; Cho, S.; Park, S. H.; Heeger, A. J.; Lee, C. W.; Lee, S. H. Nature, 2006, 441, 65 .

11. Tan, S.; Zhai, J.; Xue, B.; Wan, M.; Meng, Q.; Li, Y.; Jiang, L.; Zhu, D. Langmuir 2004, 20, 2934.

12. Tan, S.; Zhai, J.; Xue, B.; Wan, M.; Meng, Q.; Li, Y.; Jiang, L.; Zhu, D. J. Phys. Chem. B 2004, 108, 18693.

13. Bang, J. Y.; Jeong, W. S.; Park, H. S.; Chung, K. H.; Nath, N. C. D.; Lee, J. J.; Cha, E. H.; Lee, J. K. J. Kor. Electrochem. Soc. 2010, 13, in press.

14. Kern, R.; Sastrawan, R.; Ferber, J.; Stangl, R.; Luther, J. Electrochim. Acta 2002, 47, 4213.

15. Longo, C.; Nogueira, A. F.; Paoli, M. A.; Cachet, H. J. Phys. Chem. $B$ 2002, 106, 5925 .

16. Adachi, M.; Sakamoto, M.; Jiu, J.; Ogata, Y.; Isoda, S. J. Phys. Chem. B 2006, 110, 13872.

17. Gregg, B. A.; Pichot, F.; Ferrere, S.; Fields, C. L. J. Phys. Chem. $B$ 2001, 105, 1422 . 